\title{
SEISMIC DISPLACEMENT CAPACITY OF DUCTILE REINFORCED CONCRETE BUILDING SYSTEMS
}

\author{
Tom Paulay ${ }^{1}$
}

\begin{abstract}
SUMMARY
To enable acceptable seismic displacement demands to be estimated, the displacement capacity of a structural system needs to be known. This is controlled by selected performance criteria. It is postulated that the assignment of fractions of the required seismic strength of a system to its components may be arbitrary. This enables the displacement capacity of buildings to be evaluated without the knowledge of the magnitude of seismic strength. A redefinition of some traditionally used structural properties is a prerequisite for applications. The following study of reinforced concrete mixed systems illustrates rationale and extreme simplicity of application.
\end{abstract}

\section{INTRODUCTION}

Extensive research addressing issues of performancebased earthquake engineering, arrived at different approaches to the estimation of displacement demands that may be imposed on building systems by earthquakes. However, relatively few studies considered ways and means by which displacement capacities of structural systems, particularly reinforced concrete buildings comprising components with very different behavioural characteristics, could be estimated. A rational evaluation of structural displacement capacities, corresponding to specific performance criteria, should enable acceptable seismic displacement demands, associated with appropriate earthquake records, to be established. This in turn should facilitate the corresponding seismic strength of systems to be quantified. It should ensure that expected displacement demands are no likely to exceed capacities, which can be more reliably predicted and provided. This study does not address approaches to the prediction of seismic displacement demands.

To allow displacement capacities to be quantified, some traditionally used structural properties needed to be redefined. It is considered that several assumptions, particularly those related to elastic structures using homogeneous materials, do not meet realistic criteria, for example those relevant to ductile reinforced concrete systems. Some important findings of recent studies, which critically examined fallacious, yet widely used, concepts [1], were adopted in this work. This enabled displacement capacities of components and elements of structural systems to be more realistically evaluated. Moreover, such capacities may be simply related to each other.

\begin{abstract}
A behaviour-based strategy is outlined. With the aid of a commonly used lateral design force pattern, it enables the designer to estimate limiting displacements of systems about to be designed. This can be undertaken without the knowledge of the magnitude of the strength eventually to be assigned to the system. Relatively complex structures, comprising reinforced concrete walls interacting with frames and coupled wall systems, were chosen to demonstrate implementation.
\end{abstract}

The procedure avoids the use of engineering judgementbased global displacement ductility ratios, extensively used in modern building codes. Instead, it addresses displacement capacities of critical components. Such estimates enable the ductility capacity of an entire system to be determined.

To aid simplifications deliberate approximations were made. These were considered to be fully compatible with the inevitable crudeness of the predictions of earthquakeinduced displacement demands.

\section{DISPLACEMENT LIMITATIONS}

Following currently accepted seismic design aims, maximum displacements imposed on ductile systems are deemed to be controlled by:

- The displacement capacity of critical components corresponding with the adopted, i.e., codified, quality of their detailing for construction.

- The magnitude of storey drift satisfying the performance criterion, specifically chosen for the system.

\footnotetext{
${ }^{1}$ University of Canterbury, Christchurch, New Zealand (Life member)
} 
The more severe limit may then establish the target displacement capacity of the ductile system.

\section{THE TOOLS OF DISPLACEMENT ESTIMATES}

\subsection{Preliminary Considerations}

Traditionally, the structural design process starts with experience-based estimates of dimensions, particularly component sizes, which are likely to satisfy functional requirements of the building. Once this information, based on both architectural and engineering perspectives, is available, displacement estimates, adequate for purposes of seismic design, can be readily made.

\subsection{Estimates of Nominal Yield Curvature}

A fundamental property of a component is the nominal yield curvature at its critical section or sections. This will define its response in the elastic and post-elastic domain of behaviour when subjected to monotonically increasing displacements. In reinforced concrete members, it is more reliable to base this estimate on quantifiable section properties, rather than on an assumed or recommended $[2,3]$ values of flexural rigidity, $E_{c} I_{e}$, where $E_{c}$ is the modulus of elasticity of the concrete and $I_{e}$ is the second moment of the effective sectional area of the cracked component.

Figure 1(a) shows curvature relationships relevant to a typical structural wall section. With some design experience the neutral axis depth can be estimated. As stated, for purposes of seismic design a high degree of precision in the estimation of component properties is not warranted. If necessary, this estimate can be subsequently verified once details of the flexural reinforcement are known. For a given steel tensile yield strain, $\epsilon_{y}$, and the location of the neutral axis, $\xi D_{w}$, the curvature at the onset of yielding is established as $\phi_{y}^{\prime}=\epsilon_{y} /(\xi D)$, where $D_{w}$ is the overall depth of the section. When details of the reinforcement are known, the associated yield moment, $M_{y}$, may also be evaluated. However, the need for this will seldom arise. The designer will primarily address the nominal flexural strength, $M_{n}$, at a section, once strength requirements for components are known.

For seismic design purposes a bi-linear simulation of the non-linear moment curvature relationship, as shown in Figure 1(b), is adequate. With linear extrapolation this then leads to the nominal yield curvature

$$
\phi_{y}=\left(M_{n} / M_{y}\right) \phi_{y}^{\prime}=\left(M_{n} / M_{y}\right)\left[\epsilon_{y} /\left(\xi D_{w}\right)\right]=\eta \epsilon_{y} / D_{w}
$$

where the coefficient $\eta=\left(M_{n} / M_{y}\right) / \xi$ recognises the relation of nominal to yield strength and the relative position of the neutral axis. Effects of strain hardening may also be included. These, however, are not shown here.

Extensive studies of a variety of sections, conducted at the University of Canterbury, confirmed previous findings [4], that for specific types of members, such as walls or beams, the variation of the value of $\eta$ is rather small. For example, the amount of reinforcement used in a section, hardly affects yield curvature. Typical values of variables of Eq. (1), relevant to some wall sections, are assembled in Figure 2. These correspond approximately with the geometry of sections as shown. Moderate gravity-induced axial compression loads, commonly encountered in structural walls, do not affect the nominal yield curvature to any significance. However, its effect on flexural strength is very pronounced. Figure 1(b) shows this. Subsequent examples will show how simple adjustments of the parameter $\eta$ may be made when larger compression loads are present or when walls are subjected to axial tension.

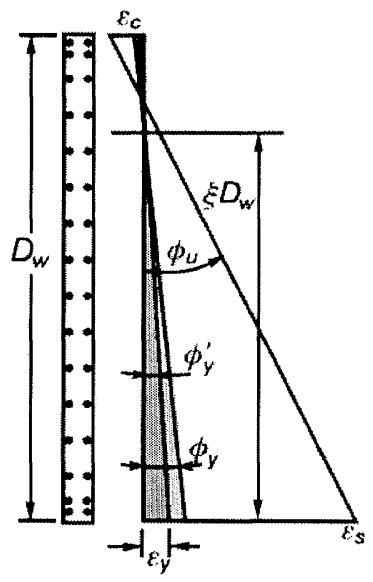

(a) Strain Patterns

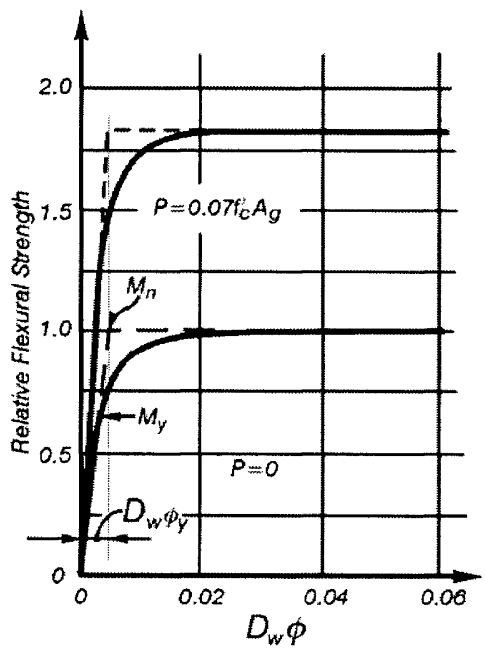

(b) Flexural Strength-Curvature Relationship

Figure 1. A definition of nominal yield curvature 
It is emphasised that values of $\eta$ in Figure 2 are estimates for typical cases. Deviations for situations corresponding to real load and detailing conditions are to be expected. Corresponding errors with respect to estimates of displacement capacities of components, the major issue in this presentation, are, in terms of seismic design, considered to be negligibly small when compared with the crudeness of the estimates of earthquake induced displacement demands.

Typical values of $\eta$ relevant to rectangular or flanged beams, rectangular and circular columns [5], were found to be $1.70,2.12$ and 2.35 , respectively.

The important message of Eq. (1) is, that nominal yield curvature should be considered as a section and material property. It is insensitive to, and for design purposes essentially independent of, section strength.

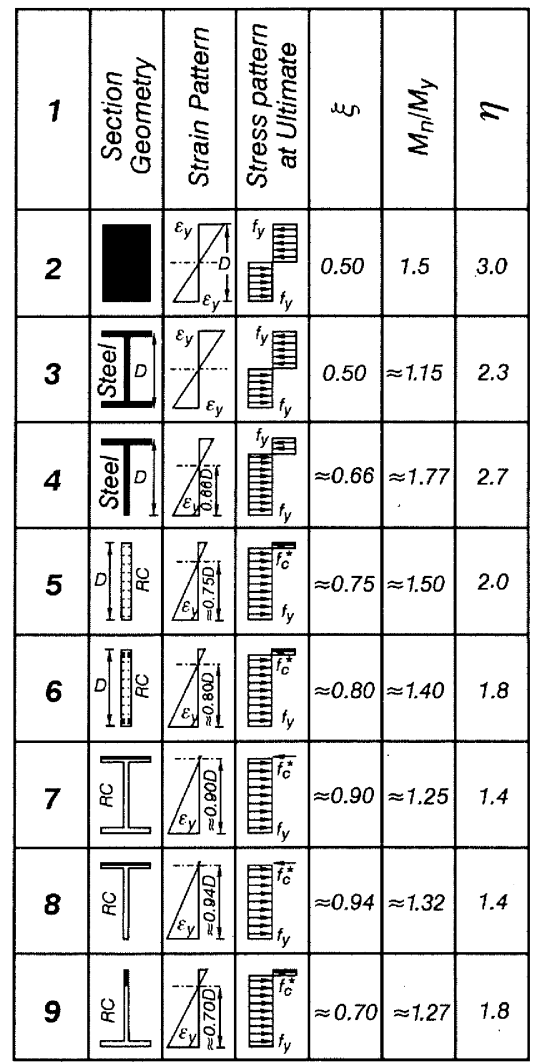

Figure 2. Parameters affecting nominal yield curvature

\subsection{Nominal Yield Displacements}

An approach, similar to that used in defining the nominal yield curvature of critical sections, based on bilinear simulation of the force-displacement relationship for a component, may be utilized. Figure 3 shows familiar features of this simulation. The strongly non-linear response of concrete component from the onset of cracking and the development of its nominal strength, $V_{i n}$, is of little interest with respect to estimations of displacements in the inelastic range of response. The shaded area in Figure 3 indicates essentially linear response after the occurrence of repeated displacements, not exceeding that associated with the yield strength, $V_{y}$, and the yield curvature, $\phi_{y}^{\prime}$, of the component. Hence the nominal strength-independent yield displacement, $\Delta_{i y}$, may be based on the nominal yield curvature, $\phi_{y}$, at the critical section, given by Eq. (1). For any component, subjected to a known moment pattern, the nominal yield displacement can thus be considered as a component property. In this study, only conservatively estimated flexural deformations of wall components were considered. If further refinements appear to be necessary, other sources of distortions, such as shear and anchorages, may be readily included. The enhancement of the nominal yield displacement of a system, resulting from deformations within the foundation system, is however briefly addressed. Subsequent examples will illustrate applications. An important conclusion, drawn from the bilinear relationship seen in Figure 3, is that component stiffness may be defined as

$$
k_{i}=V_{y} / \Delta_{y}^{\prime}=V_{i n} / \Delta_{i y}
$$

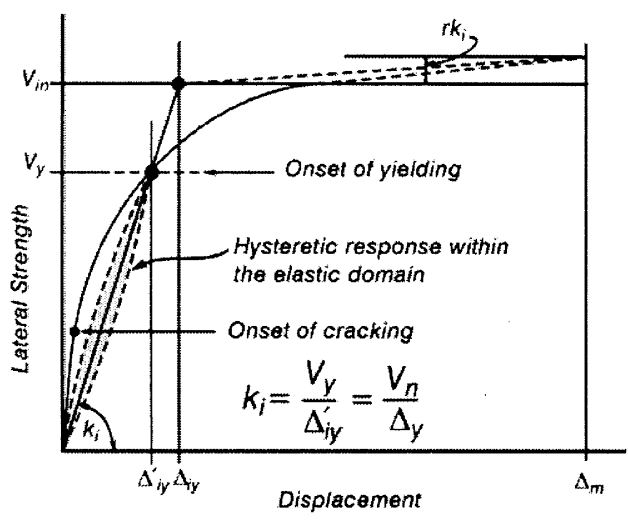

Figure 3. Force-displacement relationship for a typical reinforced concrete component and its idealisation

Contrary to traditional assumptions, Eq. (2) shows that stiffness of a component is proportional to its strength [6]. Figure 3 clearly shows the range of strengths i.e., when $V_{y}$ $<\mathrm{V}<\mathrm{V}_{\text {in }}$, over which the stiffness so defined would significantly underestimate displacements. However, in terms of the response of ductile systems, this range is generally of little interest.

The bilinear simulation also allows the displacement ductility, applicable to component $\mathrm{i}$, to be more realistically quantified as

$$
\mu_{i \Delta}=\Delta_{m} / \Delta_{i y}
$$

where $\Delta_{m}$ is the system displacement associated with a stipulated performance limit state. 


\section{FREEDOM IN ASSIGNING ELEMENT STRENGTHS}

As stated previously, the nominal yield curvature at the critical section of a component with given dimensions, and hence the relevant nominal yield displacement, may be considered for seismic design purposes to be independent of the nominal strength of the component. Therefore, fractions of the total required seismic strength may be assigned arbitrarily to components and elements of systems $[7,8]$. At any level, components of lateral forceresisting elements are assumed to be subjected to identical lateral displacements. Due to torsional phenomena, elements of structural systems may be subjected to different translatory displacements. An element, such as a cantilever wall, may comprise a single component. The implications of this freedom in assigning component or element strengths, are that:

- Irrespective of the strength assigned to components, they will commence yielding when the imposed system displacement approaches the nominal yield displacement of the relevant component.

- Simultaneous onset of yielding of components of elements with different overall depths, and hence different aspect ratios, is not possible.

- Lateral force-resisting components of a system with different nominal yield displacements, when subjected to identical translational displacements, will be exposed to different displacement ductility demands.

- A structural system, comprising elements having different nominal yield displacements, does not exhibit a distinct yield displacement. The definition of the nominal yield displacement of a system is often ambiguous and hence it needs to be redefined.

- To ensure that all components of a system will perform satisfactorily, the displacement capacity of the system should be restricted to that of the component with the smallest displacement capacity.

Arbitrariness in strength assignments imparts to the astute designer the ability to chose from a number of possible, viable and appealing solutions $[9,10]$. To illustrate the relevance of the structural features listed above, a somewhat idealised single storey system, deliberately made simple, is studied here briefly.

Figure 4(a) shows the plan of a structure in which lateral forces in the $y$ direction are resisted by five rectangular reinforced concrete cantilever walls of identical heights but with different lengths, $D_{i}$. Slender components, intended for the transmission of gravity loads only, are not shown in Figure 4(a).

Traditional design approaches would assign nominal wall strengths, i.e., base shear, in proportions of $D_{i}^{3}$. Under identical element translations this would require reinforcement ratios in Walls (1) and (3), to be $43 \%$ larger than for Walls (4) and (5). However, if wall nominal strengths are made proportional to say $D_{i}^{2}$, all walls would require the same ratio of vertical reinforcement. This would enable identical arrangement of bars to be used in all walls of the structure.

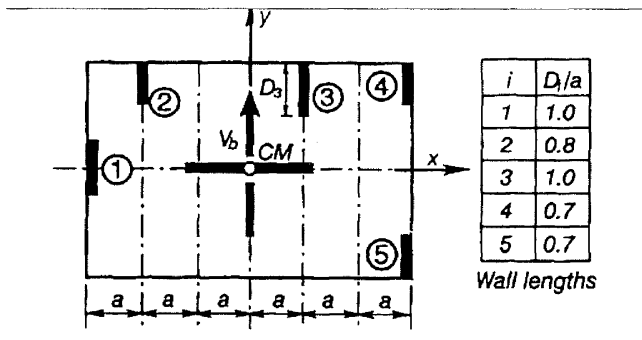

(a) Plan

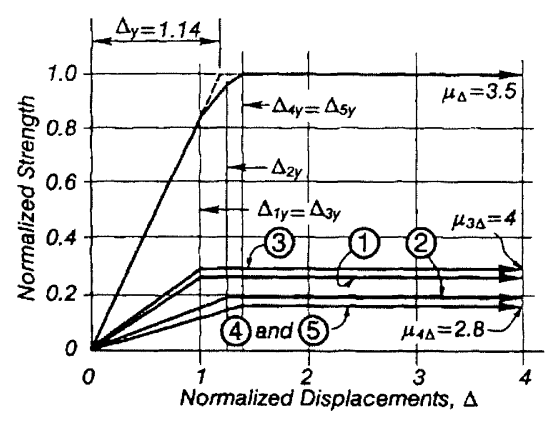

(b) Force-displacement Idealization

\section{Figure 4. The model of a wall system}

Wall strengths so provided would, however, result in this case in a strength eccentricity with respect to the centre of mass $(\mathrm{CM})$ of $-0.095 a$. With some $6 \%$ reduction of the strength of Wall (1) and a corresponding increase of the strengths of Walls (4) and (5), even this relatively small eccentricity would be eliminated. Thereby torsional phenomena, affecting element displacement demands primarily in the post-yield domain of response, would become negligible $[8,11]$, and would thus not need to be addressed. It may be shown [8] that, based on Eq. (2), the stiffness eccentricity, affecting elastic response of the model structure with no strength eccentricity, would also be rather small $(-0.21 \mathrm{a}$, i.e., approximately $4 \%$ of the length of the plan).

The bilinear simulation of the translational behaviour of the system and its 5 components is shown in Figure 4(b). Displacements plotted are normalised in terms of the nominal yield displacement of Walls (1) and (3), taken as unity. The modelling of the displacements of the example structure, comprising of components with different strength and stiffness properties, demonstrates:

- The sequence of component yielding, from that of Wall (1) to Wall (5), during monotonic 
displacements of the system. Nominal yield displacements are inversely proportional to wall lengths, $D_{i}$, and, as stated, are independent of strength assigned to them.

- The superposition of bilinear component responses results in nonlinear system response.

- Evidence that assuming bilinear simulation also of system behaviour would be justified. This assumption allows the nominal yield displacement of the system to be expressed as

$$
\Delta_{y}=\Sigma V_{i n} / \Sigma k_{i}
$$

In this example $\Delta_{y}=1.00 / 0.879=1.14$ displacement units. It is to be used as a reference value, to enable the system displacement ductility, given by Eq. (5), to be quantified. At this displacement some elements, such as Walls (1) and (3), will have entered the inelastic domain, while others are still elastic.

- The nominal yield displacement of the system, $\Delta_{y}$, with given base shear capacity, will be affected to a small, usually negligible, extent by the distribution of component strengths, $V_{i n}$.

- That, as stated previously, the translational displacement capacity should be controlled by that of the critical element, i.e., Walls (1) and (3). In this example it is assumed that appropriate detailing of all walls [2,3] allows a component displacement ductility capacity of $\mu_{i \Delta}=4$ to be relied on. Therefore, $\Delta_{m}=4 \times 1=4$ units. When the ductility capacity of the system is considered, as in strength-based seismic design procedures, the system displacement ductility capacity to be assumed should, therefore, be restricted to

$$
\mu_{\Delta} \leq\left(\Delta_{i y} / \Delta_{y}\right) \mu_{i \Delta}=(1.0 / 1.14) \times 4=3.5
$$

- That, to a relatively small degree, the choice of strength assignment to components of a system will affect its stiffness.

This simple example is presented in support and illustration of previously made claims [7], that displacement limits applicable to a ductile system and its components can be established before required strengths are determined.

When it is desired to check the behaviour of the elastic structure, subjected to lateral forces less than those associated with the known nominal flexural strength of its components, the second moment of the effective cracked concrete section, $I_{e}$, may be approximated with a relatively high degree of precision. Once the nominal flexural strength of an element, $M_{n}$, and hence the ratio of flexural reinforcement at its critical sections, as constructed, is known, verifications of the predictions of displacements in the elastic domain of response may be made, using the effective flexural rigidity

$$
E_{c} I_{e}=M_{n} / \phi_{y}
$$

where the strength-independent nominal yield curvature is given by Eq. (1) and $E_{c}$ is the modulus of elasticity of the concrete. Although the extent of cracking may vary along a component, Eq. (6) implies that the position of the neutral axis of sections, associated with the onset of yielding at the extreme tension fiber, does not change. This is one of the approximations, similar to that used in current design practice [3], the justification of which was considered in Section 3.3.

\section{REINFORCED CONCRETE COUPLED WALLS}

\subsection{Existing Design Procedures}

Even though during significant seismic events, reinforced concrete structures are expected to perform in the inelastic domain, the assignment to components of lateral design strength is still widely based on elastic structural response. In recognition of ductile behaviour, within specified limits, a redistribution between components of internal design actions, so derived, has, however, been considered acceptable $[2,3,12]$.

As Figure 5 shows, only the mode of the resistance to lateral force-generated overturning moments is different in cantilever and coupled walls. The well established equilibrium requirement for the latter is

$$
M_{o}=M_{1}+M_{2}+\ell T
$$

where the components of flexural resistance are shown in Figure 5(c). The axial force at any level, $T$, results from the summation of the shear forces transferred by coupling beams above that level. The distance between the centroidal axes of the two walls is usually taken as the lever arm, $\ell$, on which the axial forces, $T$, operate in resisting moments. These 3 moment contributions are traditionally assigned proportionally to component stiffness. The latter are based on flexural rigidities, $E_{c} I_{e}$, of prismatic components. $I_{e}$ is usually expressed in terms of a fraction of the second moment of the gross concrete sectional area, $I_{g}$. Values of $I_{e} / I_{g}$, recommended in some codes or used in publications [2,3] or design practice[13], vary in a wide range of 0.2 to 1.0 . The allocation of design strength to various components is not sensitive to such assumptions, provided that it is consistent. However, predicted displacements of elastic coupled walls may involve errors of the order of several hundred percent. In terms of the aims of performance-based seismic design, this is of great concern. A particular disadvantage of the use in seismic design of crudely estimated values of $I_{e}$, is the inability to predict realistic values of yield 
deformations of both components and the system, and hence to evaluate displacement ductilities.

Assumptions with respect to the stiffness of coupling beams were considered[2,12,14,15] to affect both the intensity and the variation with building height of the shear forces generated in coupling beams. With minor modifications $[2,3,12]$ stiffness-dependent strengths have been routinely adopted in conventional seismic design. The ratio

$$
\ell T / M_{o}=\beta
$$

quantifies the degree of coupling. Figures 5(b) and (c) illustrate examples of relatively high and low degrees of coupling. This ratio has been the subject of differing views in the relevant literature [13]. Some studies suggested[16] that there is an optimal value for $\beta$, which promises favourable dynamic seismic response. Others held the view that large lateral force-induced axial forces, $T$, would be difficult for the foundations to absorb. However, it is not likely that separate foundations for each coupled wall, i.e., a foundation structure different from that required for a cantilever wall, implied in Figure 5(a), could be contemplated. For some 25 years the use of squat coupling beams, if possible, was advocated in New Zealand design practice[2,12]. It was perceived [17] that for ductile systems, a high degree of coupling should be an efficient and in many cases the major source of energy dissipation and hence large hysteretic damping.

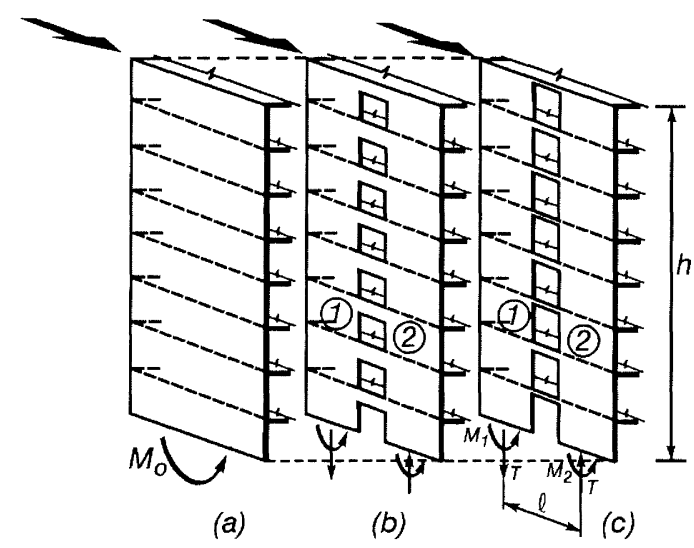

Figure 5. A comparison of flexural mechanics in structural walls [2]

\subsection{Properties of a Prototype Structure}

To illustrate application to a coupled wall structure of the principles outlined in the previous sections, a specific example was chosen. While different aspects of displacement estimates are considered, the evaluation of relevant quantities will not only be given in abstract terms, but will also be simultaneously expressed in terms of the selected structural dimensions. This should assist in the appreciation, particularly by design practitioners, of relevance of the approach to structural behaviour and the simplicity in quantifying it.

The principal dimensions of a 12 storey service core, comprising 2 channel shaped reinforced concrete coupled walls, and its relevant details, are shown in Figures 6(a) and (b). All dimensions are expressed in terms of the total height, $h$, of the building. Because reference displacements are strength-independent, for their estimation only the pattern of the lateral design forces need to be known. In terms of the unit base shear, chosen for convenience, these are given in Figure 6(e). The overturning moments and shear forces at each level of the cantilever structure with a fully restrained base, are then readily determined. They are presented in Figures 6(c) and (d).

The aspect ratio of the individual walls with length $D_{w}$ with respect to the full height, $h$, is $A_{w i}=h / D_{w}=1 / 0.135$ $\approx 7.4$. As Wall (1), shown in Figures $6(\mathrm{a})$ and (b), is expected to be subjected to significant axial tension, the location of its neutral axis, measured from the tension edge, is estimated, as suggested in Section 3.2, with the aid of the information provided in row 9 of Figure 2, i.e., with the parameter $\xi=0.83>0.70$. Considerations of Wall (2), subjected to gravity and lateral force-induced compression (row 8 in Figure 2) lead to a similar value of $\xi \approx 0.83<0.94$. With the assumption that the yield strain relevant to this example structure is $\epsilon_{y}=0.002$, we find from Eq. (1) that the nominal yield curvature factor is $\eta_{1}$ $\approx \eta_{2}=1.55$. The choice of a steel strain $\varepsilon_{y}=0.002$ enables significant differences of displacements, associated with different steel grades, i.e., smaller $\left(\varepsilon_{y}=0.0015\right)$ or larger yield strains $\left(\varepsilon_{y}=0.0025\right)$, to be appreciated.

The important property of the walls, the nominal yield curvature at the base, is thus from Eq. (1)

$$
\phi_{w y 1} \approx \phi_{w y 2}=1.55 \epsilon_{y} / 0.135 h=0.023 / h
$$

That nominal yield curvatures for two walls, although subjected very different axial loads, are, in this rather exceptional case, about the same.

\subsection{Assignment of Relative Component Strengths}

As stated in Section 4, the assignment of fractions of the total seismic strengths to components of the coupled wall structure should be the designers' experience-based choice. For the purpose of estimating wall actions, satisfying equilibrium criteria, the axes of the walls are assumed to coincide with the centroidal axes of the gross concrete sections. As Figure 6(b) shows, the distance between these axes is $\ell=0.233 h$. In this example it has been decided that $\beta=0.56$ (Eq. (8)), i.e., $\ell T=0.56 M_{o}$ at the base (Fig. 5). Hence the lateral force-induced axial force in the walls is at this level $T_{\max }=\beta M_{\delta} / \ell=(0.56 \mathrm{x}$ $\left.0.711 h V_{b}\right) /(0.233 h)=1.709 V_{b}$. Contrary to traditional procedures $[2,15,17]$, in this example, identical nominal 
shear strengths, $Q$, have been assigned to coupling beams at all levels, i.e., $Q=1.709 V_{b} / 12=0.142 V_{b}$. The practicality in construction of this choice is obvious. The moment increment introduced by the coupling beams at each level of the structure is $\Delta M=\ell Q=-0.233 h \times 0.142 V_{b}$ $=-0.033 h V_{b}($ Figures 6(c) and $(\mathrm{d}))$.

As the lateral force-induced axial load on the walls, $T$, increases from the top to the bottom (stepwise) linearly to its maximum at the base, the corresponding (stepped) wall moments $\left(M_{1}+M_{2}\right)$, are readily obtained. These are shown by the shaded area in Figure 6(c). With $V_{b}=1.00$, the sum of the base wall moments is thus

$$
M_{1}+M_{2}=(1-\beta) M_{o}=0.44 \times 0.711 h=0.313 h
$$

i.e. $44 \%$ of the total overturning moment (Eq. (7)). The presentation in Fig. 6(c) of these moments is informative because it shows clearly the effects of the chosen beam strengths on wall moment patterns. It is evident that at approximately $h_{e}=0.57 h$ above the base, wall moments became negligibly small. This enables critical wall deformations to be readily estimated. The same wall moments are presented in the more conventional form in Figure 6(d).

The final stage of strength assignment, not affecting deformation estimates for the walls, involves the distribution of the required wall flexural strength, $M_{1}+$ $M_{2}$, between components (1) and (2). This too can be done arbitrarily. As Wall (2) will be subjected to significant axial compression, it will be able to develop significant flexural strength with only a modest quantity of tension reinforcement in the vicinity of the door openings. For example the designer may choose a wall strength ratio of $M_{2} / M_{1} \approx 7 / 3$. Therefore, the total shear force to be assigned to the two walls should be $V_{1} \geq 0.3 V_{w}$ and $V_{2} \geq$ $0.7 V_{w}$, respectively. This is shown in Figure $6(\mathrm{e})$. Deformation compatibility of the two elastic coupled walls requires some (horizontal) axial forces to be developed in the coupling beams. To a small extent these tension or compression forces affect the distribution over the height of the static wall shear forces. Moreover, the lengthening of coupling beams, shown as $\Delta_{b h}$ in Figure 7, and generally unrecognised in current analyses techniques, also contributes to a redistribution of shear demands from one wall to another. These changes, not shown in Figure 6(e), particularly when compared with the eventual shear strength required to be provided, are negligibly small.

In accordance with the principles of capacity design, to inhibit the interference of possible shear mechanisms with the intended ductile response of walls, the nominal shear strength of the walls, as constructed, needs to be well in excess of that satisfying static equilibrium[2,3].

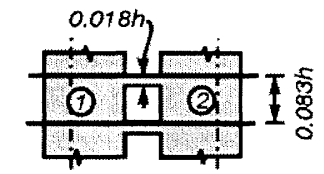

(a) Elevation

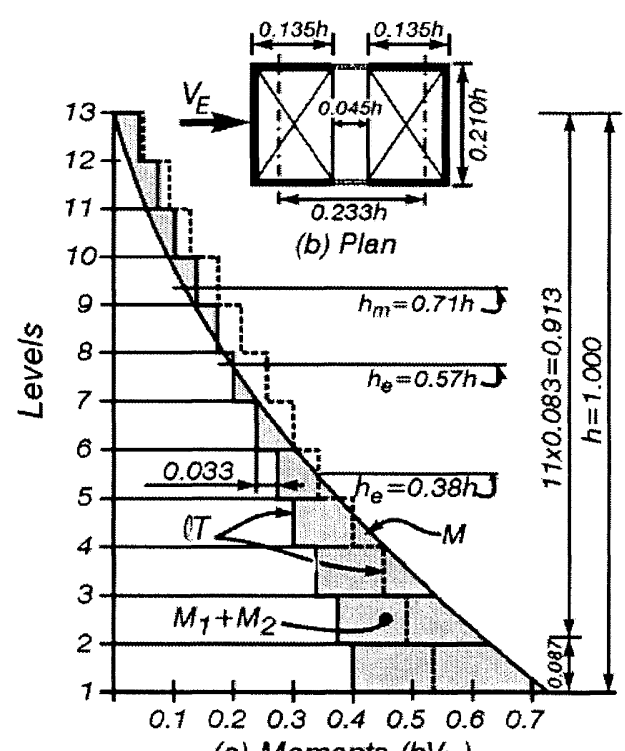

(c) Moments $\left(h V_{b}\right)$

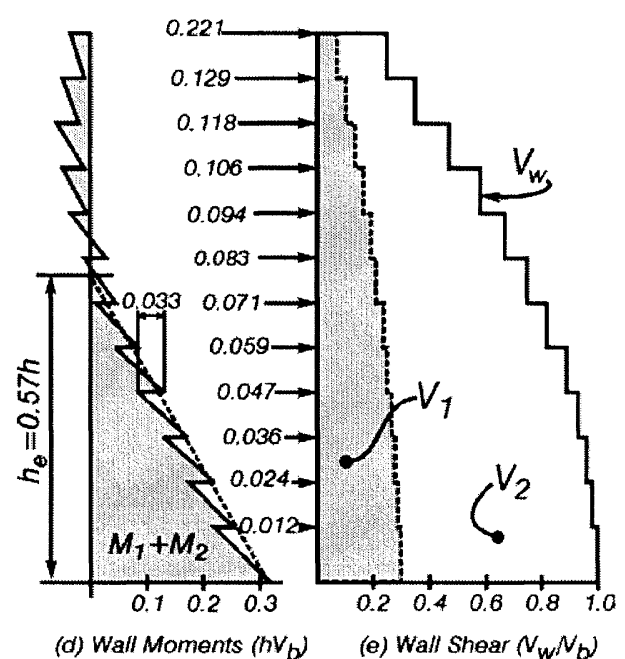

Figure 6. Principal dimensions of and design actions applicable to a coupled wall structure

Figure 6(e) also shows the commonly used distribution over the height of lateral static design forces. In this case $92 \%$ of the unit base shear was distributed in the traditional pattern of an inverted triangle, while $8 \%$ of the base shear was added to the lateral force at level 13 . Modal shapes will affect lateral force patterns relevant to elastic systems, the displacements of which, as in the cases studied in this presentation, are controlled by full height walls. Once, on account of the formation of plastic hinges at the base of the walls, the inelastic domain of wall response commences, higher modes of vibrations will 
have negligible effects on overall system displacements, such a shown in Figure 9. Therefore, any type of commonly used lateral design force pattern, leading to displacements consistent with elastic first mode response, should be considered to be adequate for the purpose of displacement estimates.

\subsection{Wall Deformations}

The typical moment pattern, applicable to the walls and shown in Figures 6(c) and (d), suggests that for the purpose of displacement estimates, linear variation of moments over the height $h_{e}=0.57 h$ may be considered. This is shown by the dashed line in Figure 6(d). Hence, using Eq. (9), the nominal yield deflection of the walls at that height may be estimated by

$\Delta_{y l}=\Delta_{y 2}=\phi_{w y i} h_{e}^{2} / 3=(0.023 / h)(0.57 h)^{2} / 3=0.0025 h$

The slope of the walls, i.e., the corresponding drift in the 7 th storey, is

$\theta_{w y} \approx \phi_{w y i} h_{e} / 2=(0.023 / h)(0.57 h) / 2=0.0066 \mathrm{rad}$

These are two important quantities. They enable displacement limits for the ductile system subsequently to be established[10, 18].

As stated at the end of Section 4, Eqs. (11) and (12) are based on the assumptions that the extent of cracking is similar at all levels of a wall. It implies that the positions of the neutral axes of wall sections at any level are the same as that derived for the base section at the onset of yielding of the tension reinforcement. While this assumption may overestimate the nominal yield displacement and rotation at the effective height, $h_{e}$, of the wall, it overcomes the unnecessary difficulty of having to use in analysis programs variable values of the flexural rigidity of wall sections, $E_{c} I_{e}$. Moreover, due to higher mode elastic vibrational effects, moments at the level of the effective height may well be significantly larger than that implied in Figure 6(d). Thus cracking in that region of elastically responding coupled walls should be expected. The estimated nominal yield displacement of walls, given by Eq. (12), may be considered to be a useful reference value, in terms of which other deformations are conveniently expressed. It is considered to be significantly more realistic than displacements based on widely used judgement-based codified values of equivalent flexural rigidity, $E_{c} I_{e}$.

\subsection{Deformations of Coupling Beams}

The behaviour of coupled walls is strongly influenced by that of the coupling beams. For efficient system response short and deep beams are preferable. When coupling beams are relatively slender, having an aspect ratio of 2 to 3 , designers may be tempted to treat them as beams in ductile frames. However, it may be shown [18] that the curvature ductility generated at the plastic hinges of such beams, when associated with the usable displacement capacity of the system, is generally well beyond achievable values. Therefore, in this study only diagonally reinforced coupling beams are addressed.

Early studies $[12,19]$ indicated that to avoid sliding shear failures in the inelastic regions of conventionally reinforced squat coupling beams, which are subjected to high reversing shear demands, diagonal reinforcement should be used. Typical details are shown in Figure 7. Such beams have been first used in New Zealand and subsequently in many other countries. Their design and behaviour has been extensively reported[2,12,19, 20, 27].

The properties of such beams are:

- The nominal strength, in terms of the shear force sustained by diagonal bars at an inclination $\alpha$ and with area $A_{s d}$, as shown in Figure 7, is

$$
V_{b n}=2 A_{s d} f_{y} \sin \alpha
$$

where $f_{y}$ is the yield strength of the steel used.

- The elongation of the diagonal bars in tension in the beams with clear span length, $s$, is

$$
\Delta_{T}=\left(s / \cos \alpha+16 d_{b}\right) \epsilon_{y}
$$

Allowance for anchorage deformations was made including 8 bar diameter length, subjected to yield strain, at each end.

For the beams of the structure shown in Figure 6(a), $\alpha \approx 18^{\circ}$ and $d_{b} \approx 0.55 \times 10^{-3} \mathrm{~h}$. Therefore,

$$
\begin{aligned}
\Delta_{T}= & \left(0.045 / \cos 18^{\circ}+16 \times 0.55 \times 10^{-3}\right) 0.002 h= \\
& 0.112 \times 10^{-3} h
\end{aligned}
$$

The shortening of the diagonal compression chord, $\Delta_{C}$, depends on the ratio of diagonal reinforcement used. An approximation, acceptable for seismic design purposes and in agreement with observed magnitudes[21], results in $\Delta_{C} \approx 0.3 \Delta_{T}$.

- The relative vertical displacement at the ends of the this beam, details of which may be seen in the Appendix, is

$$
\Delta_{b y}=1.3 \Delta_{T} /(2 \sin \alpha)
$$

Therefore, the nominal yield chord rotation of the beam, as shown in Fig. 7, is

$$
\theta_{b y}=\Delta_{b y} / s
$$


This is found for the example structure to be

$$
\begin{aligned}
\theta_{b y} & =1.3 \times 0.112 \times 10^{-3} h /\left(0.045 h \times 2 \times \sin 18^{\circ}\right) \\
& =0.00524 \mathrm{rad}
\end{aligned}
$$

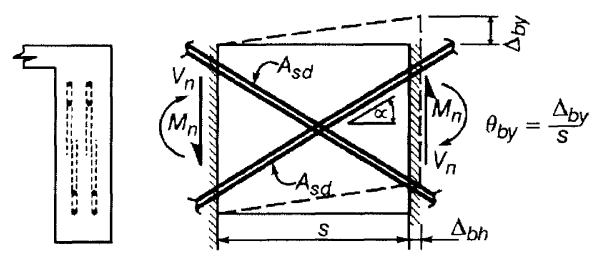

Figure 7. Nominal yield deformations of a coupling beam

The horizontal elongation of the beam, unless restrained, is

$$
\Delta_{b h}=\left(\Delta_{T}-\Delta_{\partial}\right) /(2 \cos \alpha)
$$

- If there is any effective horizontal reinforcement present, for example in a flange formed by a floor slab, the flexural resistance of the coupling beam will correspondingly increase. However, this would occur at one end only. The contribution of such reinforcement, subjected to tension only, can be readily determined[2]. Such strength enhancement will however, diminish during hysteretic response of the beam. Such horizontal reinforcement will increase beam strength significantly only when the imposed ductility demand on the beam is larger than any previously imposed one. The participation in strength development of such bars is similar to those placed in tension flanges of beams in frames.

\subsection{Relationships Between Beam and Wall Deformations}

In this section estimated displacements of the walls and those of the critical pair of coupling beams, associated with 3 distinct limit states, are compared. These states refer to (i) the nominally elastic limit of wall response, (ii) acceptable maximum storey drift and (iii) displacement ductility capacities of components.

\subsubsection{Deformations at the attainment of the nominal yield displacement of the walls}

Equation (12) estimated the maximum wall rotation, i.e., storey drift, associated with the nominal yield curvature at the wall base. The relationship between traditionally evaluated[2] rotations of two identical rectangular walls, based on $E_{c} I_{e}$, and the coupling beam chord rotations, are shown in Fig. 8(a). To estimate the relative vertical displacements of the walls, based on the traditional definition of axial stiffness[2,12], $E_{c} A_{e}$, allowance is also made for axial deformations of the walls, shown as $\Delta_{l}$ and $\Delta_{2}$ in Figure 8(a). Relative axial deformation of walls relieve chord rotations imposed on the coupling beams. The simulation implies that, under the lateral force-induced axial compression load, wall (2) shortens by $\Delta_{2}$. However, this contradicts the fact that cracked walls, encountered in practice, expand vertically unless they are subjected to extraordinarily large compression loads. Therefore, a more realistic estimate of the differential axial deformations of walls can be made if rotations are related to positions of the neutral axes of the cracked elastic walls. In the determination of these, the simultaneous actions of moment and axial force need be taken into account. With this simulation, shown for an example structure in Figure $8(\mathrm{~b})$, the ratio of the beam chord rotation, $\theta_{b}$, and the wall rotation, $\theta_{w}$, at a given level can be estimated by

$$
\theta_{b} / \theta_{w}=\left(D_{w}+c_{1}-c_{2}\right) / s=\omega
$$

where the relevant dimensions are defined in Figure 8(b). This magnification factor, $\omega$, affects dramatically displacement demands on coupling beams. For the channel shaped walls of the example structure it was estimated that $c_{1} \approx c_{2} \approx 0.023$. In this unusual case the rotation magnification relevant to the beams is simply

$$
\omega=D_{w} / s=0.135 / 0.045=3
$$

Hence with the known nominal yield rotation of the walls, given by Eq. (12), the beam chord rotation in the vicinity of level 8 is estimated as

$$
\theta_{b}=\omega \theta_{w y}=3 \times 0.0066=0.02 \mathrm{rad}
$$

This is significantly larger than the nominal yield chord rotation of an identical but conventionally reinforced coupling beam. Using Eq. (15c) the displacement ductility imposed on the critical diagonally reinforced coupling beam at this nominal elastic limit stage of the walls is, therefore, in the order of

$$
\mu_{b}=\theta_{b} / \theta_{b y}=0.02 / 0.00524 \approx 3.8
$$

It may thus be readily shown that at the development of nominal yield curvatures at the wall bases, all diagonally reinforced coupling beams would have yielded. Therefore, the development at this stage of all strength components, i.e., $M_{l}, M_{2}$ and $\ell T$, shown in Figure 5(c), can be expected.

\subsubsection{Deformations at the attainment of the limiting storey drift}

For the purpose of illustrating application, it is assumed that the adopted performance criterion restricted the maximum storey drift to $\delta_{u}=1.5 \%$. Equation (12) established that, at the attainment of the nominal yielding of the walls, the critical drifts in the vicinity of level 8 was $\theta_{w y}=\delta_{y}=0.66 \%$. The additional drift, $\delta_{p}=1.5-0.66=$ $0.84 \%$, requires plastic hinge rotations at the wall base. A 


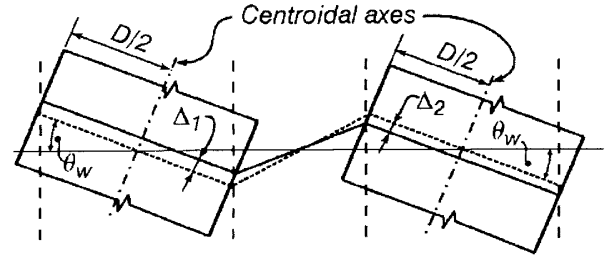

(a) Homogeneous walls

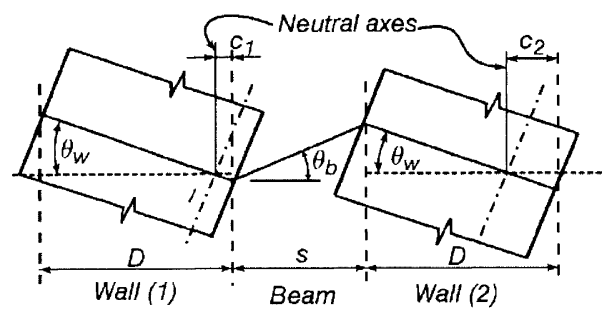

(b) Cracked concrete walls

Figure 8. Relationships between wall and coupling beam rotations

recommended[2] effective length of a plastic hinge at the base of a cantilever wall is

$\ell_{p}=0.2 D_{w}+0.044 h_{e}=(0.2 \times 0.135+0.044 \times 0.57) h=$ $0.052 h$

i.e., in this case $40 \%$ of the length, $D_{w}$, of the walls. Therefore, lateral post-yield displacement at the level of maximum drift needs to be

$\Delta_{p}=\left(h_{e}-0.5 \ell_{p}\right) \delta_{p}=(0.57-0.5 \times 0.052) 0.0084 \mathrm{~h}=0.0046 \mathrm{~h}$

The total displacement at level $h_{e}$, using Eq. (11), is thus

$\Delta_{u}=\Delta_{y J}+\Delta_{p}=(2.5+4.6) 10^{-3} h=0.0071 h$

implying a displacement ductility demand on the walls of

$$
\mu_{w}=\Delta_{u} / \Delta_{y l}=7.1 / 2.5 \approx 2.8
$$

The corresponding chord rotation of the diagonally reinforced coupling beams at level 8 will be in the order of $\theta_{b m}=\omega \delta_{u}=3 \times 0.015=0.045 \mathrm{rad}$. From Eq. (15c) the displacement ductility demand on this pair of beams is thus

$$
\mu_{b}=\theta_{b m} / \theta_{b y}=0.045 / 0.00524 \approx 8.6
$$

which, with Eq.(15a), translates into a steel tensile strain ductility in the order of $\mu_{\varepsilon}=8.6 / 1.3=6.6$. The maximum steel tensile strain to be expected is thus only $\epsilon_{\text {smax }} \approx 1.3 \%$.
5.6.3 Deformations at the attainment of the displacement capacity of the walls

Assuming that the displacement ductility capacity of adequately detailed walls[2,3] is 5 , an inelastic displacement, additional to that at the $1.5 \%$ drift limit, of $(5-2.8) \Delta_{y l}=2.2 \times 0.0025 h=0.0055 h$ of the walls would need to be accepted at level $h_{e}$. Using Eq. (11), the associated lateral displacement near level 8 of $\Delta_{\max }=5 \mathrm{x}$ $0.0025 h=0.0125 h$ would increase the maximum storey drift to $\delta_{\max }=2.5 \%$. The displacement ductility demand on the critical coupling beam and the maximum steel strain would increase to $\mu_{b}=14.3$ and $\varepsilon_{\text {smax }}=2.2 \%$, respectively.

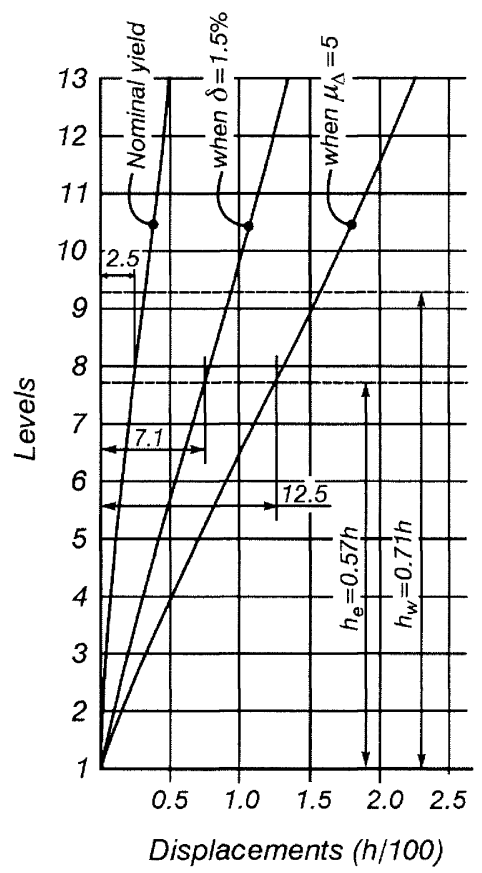

Figure 9. Wall deformations associated with three limit states

\subsection{System Response}

The estimated deformed shapes of the walls and lateral displacements just below level 8 , associated with the previously defined 3 limit states, are shown in Figure 9. The previously defined displacements at the critical level, $h_{e}=0.57 h$, are distinctly recorded.

For the purposes of seismic design, the bilinear modeling of the ductile response of this example structure, as shown in Figure 10, was claimed[6] to be entirely adequate. Lateral displacements of the walls shown in Figure 10 relate to the approximate level of accelerated mass at $h_{m}=$ $0.71 h$ above the base. These displacements can be readily extrapolated from those previously evaluated at a lower level, i.e., at $h_{e}$, (Figure 9). A small strength increase with post nominal yield deformations, having negligible influence on the response of the system, has not been 
considered. Displacement ductilities, associated with the 3 selected limit states, are also recorded in Figure 10. This simple modeling, based on realistic displacement estimates, for a single mass system, may well replace popular pushover analyses techniques.

The choice of the contribution to the total flexural strength of the system by the coupling beams, that is, the $\ell T$ component seen in Figure 5(c), determines the height at which the maximum storey drift can be expected. If the $\ell T / M_{o}$ ratio would have been chosen 0.75 , instead of 0.56 , the maximum drift should have been expected in the 5 th storey, i.e., at $h_{e}=0.38 h$. The corresponding moments to be resisted by the walls are shown in Figure 6(c) by the dashed stepped lines. This choice, requiring $34 \%$ increase of beam strengths, would have led to $33 \%$ reduction of the critical nominal yield drift. The displacement contribution of the walls at the $1.5 \%$ drift limit, expressed in terms of their displacement ductility, $\mu_{w}$, would have increased from 2.8 to 4.3 . This alternative solution illustrates how more efficient utilisation of energy dissipation and hysteretic damping could be achieved by deliberate

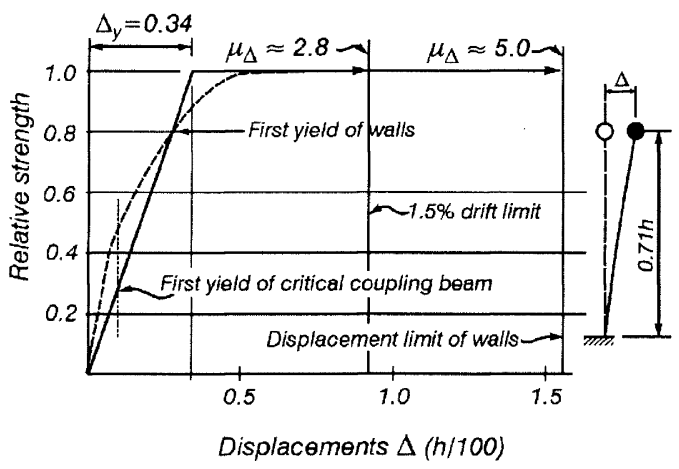
Figure 10. Bilinear modeling of the ductile behaviour
of a coupled wall structure

increase of the contribution of the very ductile coupling system to the resistance of overturning moments.

It is re-emphasised that, as Eqs. (9) and (11) have shown, displacement limitations are strongly influenced by the yield strength of the reinforcement used. For example if steel with $25 \%$ larger strength, i.e., $\epsilon_{y}=0.0025$, was to be used, nominal yield displacements would correspondingly increase. At a drift limit of $1.5 \%$ the displacement ductility demand on the walls would reduce from 2.8 to 2.2. In the current force-based seismic design method, used in New Zealand, the corresponding design base shear for the system would need to be increased, negating partly the economic advantages which the use of higher strength steel would offer.

\subsection{Test Performance}

The hysteretic performance of an approximately one quarter size reinforced concrete coupled wall model is reproduced in Figure 11. The test, the results of which were obtained nearly 30 years ago, were reported $[12,20,21]$. The pattern of overturning moments, corresponding to three identical horizontal forces, resembles closely that shown in Figure 6(c). Due to strain hardening of the steel, with $\varepsilon_{y}=0.0015$, the nominal strength of the unit was exceeded by some $18 \%$. The observed system displacement ductility of 8 corresponds to a lateral displacement at the top of the specimen of $1.8 \%$ of its height. The notation used in the original report was retained in Figure 11.

\section{DUCTILE REINFORCED CONCRETE DUAL SYSTEMS}

A very attractive mode of seismic resistance in medium to high rise buildings may be achieved with the use of interacting ductile cantilever walls and frames, extending over the full height. Displacement compatibility at every floor is assumed to be assured by means of infinitely rigid floor diaphragms. The traditional design approach to the distribution of strength to different elements, based on elastic behaviour, was extensively studied[2] . However, issues of displacement predictions relevant to this type of ductile structures, are likely to be less familiar[10,22]. Because the strong similarity in coupled wall and frame-wall structures of the interaction of elements, only a brief review of a dual system is presented here.

A prototype structure, shown in Figure 12(a), will again be used to illustrate some of the postulated, yet unconventional, design concepts. A symmetrical 10 story reinforced concrete building comprises seven frames and two cantilever walls with an aspect ratio of $A_{r w}=5.3$. Dimensions used are in terms of the height, $h$, of the building. For modelling purposes these elements are condensed into only two elements, comprising 7 frames and 2 walls, respectively, as seen in Figure 12(a). The lateral seismic design forces of the type seen in Figure 6(e) lead to overturning moment and shear force patterns, presented in Figures 12(b) and (c). In the preliminary design, the possible assignment of lateral forces to the two, rather different, elements and the associated displacement limits, are of primary interest. It is restated that, within rational limits, fractions of either overturning moments, $M$, or storey shear forces, $V_{s}$, to be sustained by the ductile mechanism of the system, may be assigned to the walls and the frames in an arbitrary manner. 


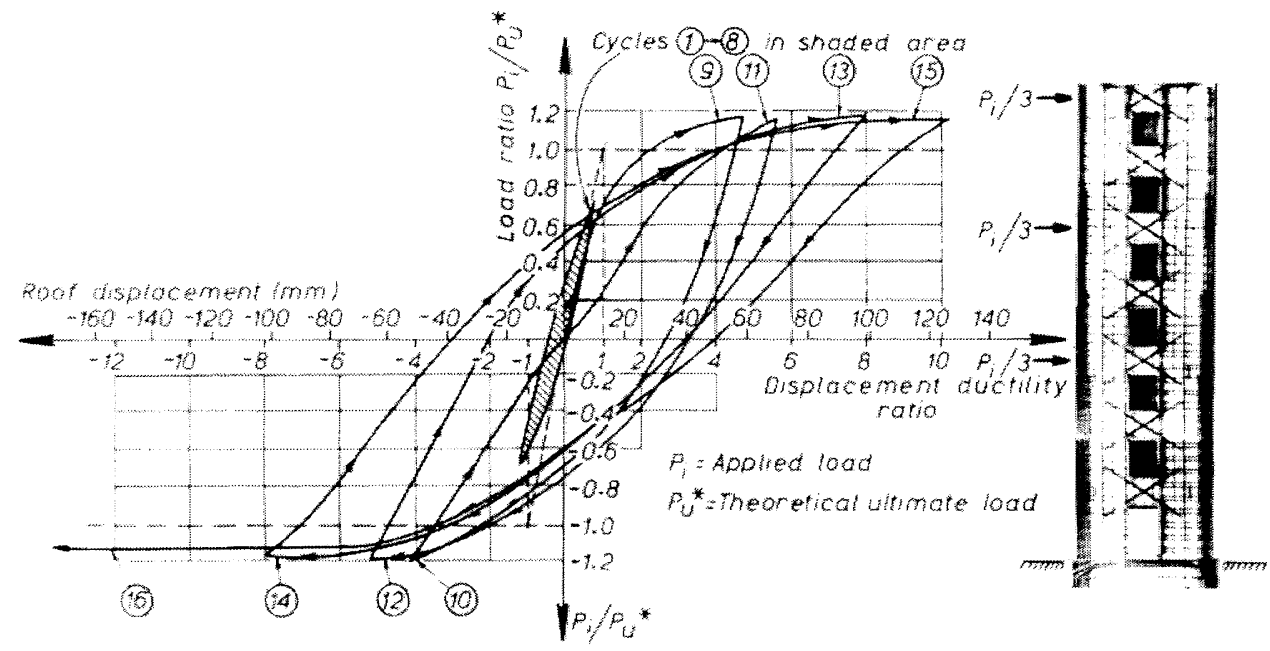

Figure 11 The hysterestic response of a test unit [21]

\subsection{The Assignment of Relative Element Strengths}

One consideration, encountered in practice, could be a limit on the transmission of relatively large overturning moments by the two walls. These moments may impose excessive demands on the foundations. Moreover, deformations of the foundation structure may jeopardize traditional assumptions of full rotational restraint at the base of the walls.

An attractive solution could result in beams, which would be subjected at the ultimate limit state to identical seismic demands. This implies that all beams, carrying also identical gravity loads, could have the same dimensions and identically detailed reinforcement. All prototype columns, although carrying different axial loads, would be subjected to near identical moment demands. Consequently, to ensure a strong-column-weak beam ductile frame mechanism, columns above level 2 could be readily provided with sufficient reserve flexural strength, to ensure that they would respond in the elastic domain. Therefore, the nominal story moment capacities for all frames, i.e., the product of the storey shear and storey height, would be made identical. The corresponding shear forces across the upper nine storeys of the frames, associated with the nominal strength of beams, would be the same. The development of identical nominal storey strengths over the full height of the frame would thus correspond to the application to it of a single lateral force at roof level. In this example it was judged that this horizontal roof level force, shared by 7 frames, could be $35 \%$ of the total base shear, i.e., $5 \%$ per frame. As Figure 12(c) shows, with this decision, the contributions of walls and frames to the resistance of the storey shear forces, $V_{s}$, are determined. Subsequently diaphragm forces, associated with these strength allocations, with appropriate magnifications for dynamic effects, will need to be carefully considered[23].

With this assignment of storey shear forces, the contribution of the condensed frame element to the resistance of the overturning moments, $M$, will increase linearly from level 11 to its maximum, $0.35 V_{b} h$, at the base. The remainder of the overturning moment, to be resisted by the two walls, is shown by the shaded area in Figure 12(b). In this example the total overturning moment at the base of the system would be resisted by the 2 condensed elements, shown in Figure 12(a), in close to equal proportions.

\subsection{Displacement Considerations}

\subsubsection{Wall deformations}

It was established that nominal yield deformations are proportional to the yield strain of the steel used. To simplify subsequent expressions and to provide a better feel for relative magnitudes, it will be assumed again that in this example $\epsilon_{y}=0.002$, i.e., $f_{y} \approx 400 \mathrm{MPa}$.

As Figure 12(b) shows, with the close vicinity of the location of zero wall moment to the effective height of the wall, $h_{e} \approx 0.6 h$, for seismic design purposes, the moment pattern for the wall over this height may be assumed as being linear. With the use of eq. (1), with $\eta=1.8$ (Figure 2), the nominal yield curvature at the base of the wall element is

$$
\phi_{w y}=1.8 \times 0.002 /(0.189 h)=0.019 / h
$$

leading to the nominal yield displacement at level $h_{e}$ of

$$
\Delta_{w y} \approx \phi_{y} h_{e}^{2} / 3=0.019 \times(0.6 h)^{2} /(3 h)=0.0023 h
$$




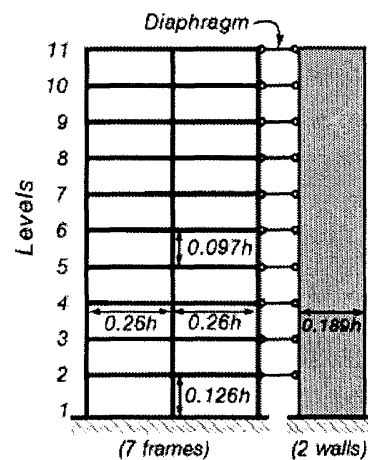

(a) The model structure

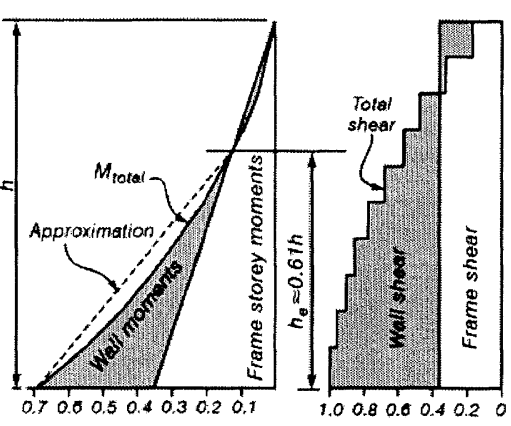

(b) Overturning moments $\left(M / V_{b} h\right)$ (c) Shear forces $\left.N_{b}\right)$

Figure 12. A frame-wall dual system

By similarity to eq. (12), the slope of the wall at level $h_{e}$ is

$$
\theta_{w y} \approx 0.019 \times 0.6 / 2=2.9 \epsilon_{y}=0.0058 \mathrm{rad}
$$

\subsubsection{Storey deformations of frames}

Interstorey yield deformations of frames in which the yielding of columns is suppressed by appropriate capacity design techniques, originate primarily from yield curvatures in the potential plastic hinges of beams. Additional elastic deformations will occur due to shear distortions in beams, columns and joints, and flexural deformations of columns. Because, compared with the yield rotations of beams, the contribution of elastic deformations in frames is relatively small, these may be approximated. By assessing the contributions to displacements of the sources listed above, it has been shown[24] that a reasonable estimate, particularly for preliminary studies, of yield drifts in storeys of frames, is

$$
\theta_{f y} \approx 0.5 \epsilon_{y} A_{r b}=6.1 \epsilon_{y}=0.0123 \mathrm{rad} .
$$

where $A_{r b}$ is the aspect (span/depth) ratio of the beams, in this example taken as 12.3 .

\subsubsection{Ductility relationships}

A comparison of the wall rotation and storey yield drift at level $h_{e}$, obtained in Eqs. (25c) and (26), shows that, at nominal yielding of the wall base, the drift in the critical storey, will be only $\theta_{w y} / \theta_{f y}=2.9 \epsilon_{y} / 6.1 \epsilon_{y} \approx 48 \%$ of the yield drift of the frame. As expected, wall deformations will control system deformations. In contrast with the coupled wall system, considered in Section 5.6.1, the walls of this dual system will need to develop significant ductility before the full seismic strength of the frames could be mobilized.

If the maximum lateral displacement of any part of system is to be limited by say $2.5 \%$ storey drift, the plastic hinge rotation at the wall base, $\theta_{w p}$, will also need to be limited to ensure that the wall rotation at level $h_{e}$, does not exceed $\theta_{w \max } \approx \theta_{w y}+\theta_{w p}=0.025$. Using Eq. (25c) the acceptable plastic rotation at the wall base is thus

$$
\theta_{w p}=0.025-0.0058=0.0192 \mathrm{rad} \text {. }
$$

The corresponding plastic wall displacement at level $h_{e}$ is, therefore,

$$
\Delta_{w p}=\left(h_{e}-0.5 \ell_{p}\right) \theta_{w p} \approx 0.95 h_{e} \theta_{w p}=0.0109 h
$$

where the length of the equivalent plastic hinge at the base of the walls was assumed[2], $\ell_{p}=0.1 h_{e}$, i.e., $32 \%$ of the length $(0.189 h)$ of the walls.

Therefore, from Eqs. (25b) and (28), the displacement ductility demand on the walls should be limited to

$\mu_{w \Delta} \approx 1+\Delta_{w p} / \Delta_{w y}=1+0.0109 / 0.0023=5.74$

which is a little in excess of the ductility capacity [3] of a well designed and detailed cantilever wall, 5.0, with an effective aspect ratio of $A_{r e}=0.6 / 0.189=3.17$. Therefore, the maximum anticipated storey drift, associated with a wall displacement ductility capacity of $\mu_{w \Delta}=5$, should be limited to:

$\theta_{w \max }=\theta_{w y}+\left(\mu_{w \Delta}-1\right) \Delta_{w y} /\left(0.95 h_{e}\right)=0.0058+$ $4 \times 0.0023 h /(0.95 \times 0.6 h)=0.0219 \mathrm{rad}$.

The corresponding maximum storey displacement ductility demand on the frames in the vicinity of level 7 will be (Eq. (26))

$$
\mu_{f \Delta}=\theta_{w \max } / \theta_{f y}=0.0219 / 0.0123=1.78
$$

Storey displacement ductility demands for the frames should be less in other storeys. 


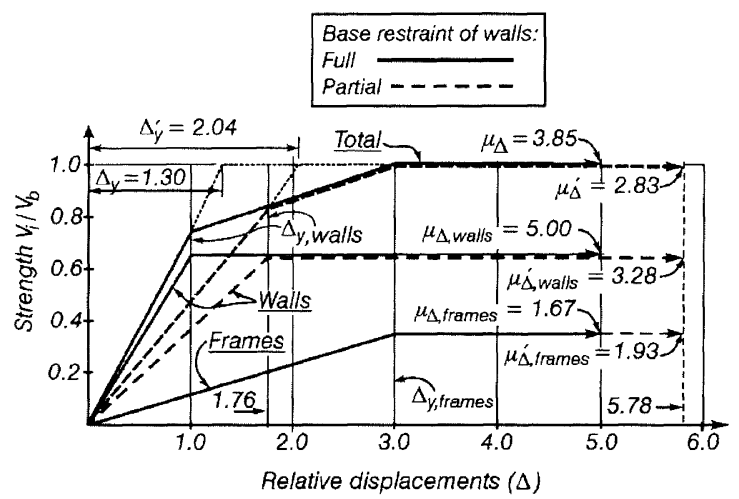

Figure 13. Bilinear simulation of force-displacement relationships for a dual system

These findings demonstrate that, in general, the full ductility capacity in dual systems of frames, cannot be utilised. The evidence obtained is of importance, as it may advantageously affect the subsequent detailing of frame components.

\subsubsection{Stiffness relationships}

This preliminary study of an example dual structural system enables also ductility relationships between the elements i.e., walls and frames, and the total system to be studied. These relationships are not likely to change substantially as the detailed design progresses. Figure 13 shows the approximate bi-linear modeling based on evaluations of displacement relationships.

Lateral displacements at level $h_{e}$ are normalised in terms of the nominal yield displacement of the walls (eq. (25b)), i.e., $0.23 \%$ of the height, $h$. Because nominal storey shear forces of the frames will develop gradually only after the walls entered the inelastic domain, estimates need to be made with respect to the contributions of the different stories to the total nominal base shear capacity of the seven frames, $0.35 V_{b}$. The sole purpose of this exercise is to estimate what the nominal yield displacement of the mixed system is. It is evident that the nominal yield displacements of the walls and frames are very different. The yield displacement of a wall can be uniquely defined. However, this is not possible for a typical frame. With identical beam dimensions at all levels, as assumed in this example, from Eq. (26) the nominal yield displacement of the frames at level 7 is in the order of $0.0123 h_{e} \approx 3.2 \Delta_{w y}$ However, designers may choose beams at upper levels to have reduced depth. This would result in some increase of the nominal yield displacement of the frames.

Approximations suggest that the nominal strength of every storey of the 7 frames, $0.35 \mathrm{~V}_{\mathrm{b}}$, can be expected to have developed only when the relative displacement at the reference level, $\mathrm{h}_{\mathrm{e}}$, approaches 3 normalised displacement units. This then allows the relative stiffness, $k_{i}=V_{i n} / \Delta_{i y}$, of the two types of elements to be estimated as $k_{\text {walls }}=$ $0.65 V_{b} / 1=0.65$ and $k_{\text {frames }}=0.35 V_{b} / 3 \approx 0.12$. These result in a total relative stiffness of $\Sigma k_{i}=0.77$. Hence from Eq. (4) the nominal system yield displacement is $\Delta_{y}=1.00 / 0.77 \approx 1.30$. The bi-linear simulation of the response of the condensed frame and wall elements is presented in Figure 13. With displacements at level 7 restricted to 5 units, the displacement ductility relevant to the frames reduces to $5 / 3=1.67$. To ensure that the intended drift limit of $2.2 \%$, given by Eq. (30) and necessitated by restriction of the wall displacement ductility capacity to $\mu_{w a}=5.0$, will not be exceeded, the displacement ductility demand imposed on the system should not exceed $\mu_{\Delta}=5 / 1.3=3.85$. When using a strength-based design approach, the design force reduction should consider this system ductility capacity, rather than a customarily nominated global value.

\subsection{The Influence of Wall Base Restraint}

In real structures the traditional assumptions of full rotational restraint at the base of walls will seldom be fully satisfied. The transmission of the nominal strength of cantilever walls to an elastic foundation structure will inevitably result in some rotation of the wall base [25]. To gauge the sensitivity of elements of a dual system with respect to this type of foundation deformation, a brief review of the phenomenon is presented.

To enable specific quantities to be estimated and compared with those previously derived, it is assumed that foundation deformations introduce a base, and hence rigid body, rotation to the walls in the order of $50 \%$ of the nominal yield rotation, i.e., storey drift at level $h_{e}$. Thereby the nominal yield displacement at that level, given by Eq. (25b), will increase by $76 \%$. The stiffness of the wall element reduces accordingly (Figure 13).

If $2.5 \%$ storey drift is considered to quantify the design limit state for this structure, for which the assignment of seismic strength to elements remains as previously decided, the post-yield displacement demands on the walls, evaluated with Eqs. (27) and (28), need to be revised. It is then found that the displacement capacity of the system, controlled by that of the wall element, 
increases by $16 \%$ to 5.78 displacement units. It is important to note, however, that, because the post-yield wall displacements associated with two cases of base restraint considered, are nearly the same (Figure 13), the critical curvature ductility demands in the plastic hinges of the walls remain unchanged. In terms of Eqs. (2) and (3), the stiffness and the displacement ductility capacity of the system will reduce by $36 \%$ and $24 \%$, respectively. These changes are shown by the dashed lines in Figure 13 and may be compared with the characteristics of the system with walls fully restrained at the base. Depending on whether a force- or a displacement-based [26] design approach is used, the changed properties will affect differently the absolute magnitude of the design seismic base shear for the system.

\subsection{Special Features of Ductile Dual Systems}

When comparing the ductile seismic responses of buildings in which lateral force-resistance is provided by frames or by walls only, distinct advantages of the use of dual systems, such as examined in the previous sections, may be identified.

Reinforced concrete walls of dual systems, when designed and detailed in accordance with the principles of capacity design, can be expected to remain elastic over their full heights above the potential plastic region at the base. This involves the curtailment of the vertical flexural reinforcement in accordance with a moment envelope which makes allowances for wall moment magnifications at upper levels of the structure due to dynamic higher mode effects. Moments in the extensive elastic region of wall will be rather sensitive to such effects. Another, even more serious, requirement is the consideration of dynamic shear magnifications at all levels [28]. Once these design criteria are satisfied, the displacement profile of a ductile dual system will be overwhelmingly controlled by wall deformations.

As the examples have shown, relationships between nominal yield, i.e., essentially elastic, deformations of a wall and those due to plastic hinge formation at its base, to be established by the designer, are extremely simple.

Lateral displacements imposed on the frames during the ductile response of the dual system are dominantly controlled by the first mode shape of the walls. Subsequent possible changes of elastic wall deformations at levels above plastic region at the base, will have negligible effects on deformation demands which may arise for the frames. Therefore, unintended development of so called soft stories or excessive storey drift demands in any storey of the frames, should not be expected.

Because inelastic deformations of the system will follow an essentially first mode shape, strength and deformation demands imposed on the frames can be readily estimated.
If a strong column - week beam frame system is desired, as in the example illustrated in Figure 12, the reserve flexural strength, to be assigned to columns in the upper stories, to prevent or delay plastic hinge formation in columns [3], can be significantly reduced. If long span beams, the strength of which may be dominated by gravity load demands, are to be used, the provision of strong columns may be difficult. In such cases the plastic mechanism of the frames may be based on simultaneous column hinges at the top and bottom of every storey. This would convert the frame into an acceptable strong beam weak column system.

As story yield displacements of frames are relatively large, inelastic story displacement demands, controlled by the walls, will be generally associated with moderate curvature ductility demands on frame components. This enables, if desired, some relaxation in the detailing requirements[3] of plastic regions in beams or columns.

It was seen that in both coupled wall structures and dual systems, displacement capacities are best expressed in terms of deformations at the effective height, $h_{e}$, of the wall elements shown in Figures 6 and 12. This level depends on the designer's choice of the relative strengths of coupling beams or frames, respectively. Considerations of storey drift at this level, associated with the nominal yield curvature at the base of the wall element, will give a good indication with respect to the desired value of $h_{e}$. From Eqs. (1) and (12) the drift angle associated with the nominal strength of the wall element is

$$
\theta_{w y} \approx \phi_{w y i} h_{e} / 2=\left(0.5 \eta \epsilon_{y}\right) A_{r w e}
$$

where $A_{n w e}=h_{e} / D_{w i}$ is the effective aspect ratio of the wall element. To illustrate relevance of Eq. (32), let it be assumed that the maximum acceptable nominal yield drift for this dual system is in the order of $0.6 \%$. Using the data quoted in Section 6.2.1, it is then found from Eq. (32) that $A_{\text {nve }} \approx 0.006 /(0.5 \times 1.8 \times 0.002)=3.33$. Hence the desirable level of zero wall moment is $h_{e}=A_{n v e} D_{w i}=3.33$ $\mathrm{x} 0.189 h=0.63 h$. This is very close to what was previously obtained by assigning $35 \%$ of the base shear (Figure 12(c)) to the frame element.

The prerequisite for efficient displacement and strength control that walls of dual systems can offer, is, of course, effective rotational base restraint of the walls by a stiff foundation structure. When significant foundation deformations, associated with the development of the nominal flexural strength of the wall base, are expected, the nominal yield drift may become excessive. An example was considered in Section 6.3.

In such cases both the wall base moment and the nominal yield rotation of the wall element, i.e., the relevant storey drift (Eqs. (12) and (25c)), at the effective height, $h_{e}$, must be reduced. This is only possible if the level at which the 
wall moment becomes zero (Figure 12(b)), is lowered. This can be readily achieved by assigning a larger fraction of the system base shear, $V_{b}$, (Figure $12(\mathrm{c})$ ) to the frame element.

The designer may, for example, chose one half of the base shear to be assigned to each of the two elements shown in Fig. 12(a). Thereby the contribution of the frame to the total overturning moment will increase by a factor of $50 / 35=1.43$, and the wall base moment wall reduce to $0.20 V_{h} h$. When plotted, the level of zero wall moment will be found to be at $h_{e}=0.43 h$. Consequently the strength-independent wall rotation, associated with the nominal yield curvature at the wall base, given by Eq. (25c), will reduce by some $30 \%$. Equation (32) would confirm that the effective aspect ratio of the wall needs to be reduced from 3.33 to 2.33 . This would allow the nominal yield drift (approximately to $0.4 \%$ ) to be increased by some $50 \%$ due to foundation rotation, without violating the perceived serviceability limit drift of $0.6 \%$.

This brief discussion of the influence of foundation deformations was intended to demonstrate, how, with suitable adjustment of the contribution of the two elements of the dual system, with given dimensions (Figure 12(a)), displacement criteria can be satisfied.

\section{ESTIMATION OF THE REQUIRED SYSTEM STRENGTH}

Because the stiffness of the system, $K_{s}$, is not a priori known, rapidly converging, experience-based, successive approximations may be used when the required nominal seismic strength, $V_{n}$, is evaluated. The simple steps involved, and based on the knowledge of the strengthindependent displacement capacity, $\Delta_{u}$, of the system, are summarized here. Limitations on displacement capacities were presented in Section 2.

\subsection{Force-based Design Approach}

As the displacement ductility capacity of the system, $\mu_{4}$ based on the properties of its most critical component, is known, the relevant design acceleration spectrum is immediately identified. The required seismic strength, $V_{n}^{\prime}$, usually based on experience-based anticipation, may then be assumed. This leads to the corresponding stiffness $K_{s}$ $=\Sigma k_{i}=V_{n}^{\prime} / \Delta_{y}$ of the system. The yield displacement of the system is established by Eq. (4). The fundamental period of vibration, $T^{\prime}$, of the structure can now be determined and reconciled with the spectral value $T$. The discrepancy between the two values of the period, $T$ and $T^{\prime}$, will then immediately indicate how the required seismic strength needs to be adjusted.

\subsection{Displacement-based Design Approach}

Based on a similar estimation of the required strength, $V_{b}^{\prime}$ and the displacement capacity, $\Delta_{u}$, of the system, its equivalent stiffness [25], $K_{s}=V_{n}^{\prime \prime}\left(\mu_{\Delta} \Delta_{y}\right)$ and hence its period, $T^{\prime}$, may be derived. With the appropriate choice of the value of damping [25,26] a new value of the required system strength, $V_{n}^{\prime \prime}$, is obtained, and satisfactory convergence of values is speedily achieved. The excellent damping properties of well detailed coupled wall structures, such as shown in Fig. 11, may be noted.

\section{CONCLUDING REMARKS}

- To satisfy the intents of performance-based seismic structural design, the importance of more realistic predictions of target displacement capacities should be recognised. For reinforced concrete structures, addressed here, such displacement limits can be readily and realistically predicted in a rather simple way without the knowledge of the eventual seismic strength required. Therefore, displacement estimates made during the preliminary stage of the design, can immediately expose undesirable features of the contemplated structural system.

- The use of a number of simple principles, often overlooked or ignored in seismic design, was demonstrated. These include: (a) The stiffness of a reinforced concrete component may be considered to depend primarily on the nominal strength eventually assigned to it. Therefore, element or system stiffness cannot be a priori assumed. (b) The nominal yield curvature of a reinforced concrete section, which represents a characteristic strain pattern, and displacements of a component associated with it, are insensitive to the flexural strength of the section. (c) Because deformation limits, applicable to components of a ductile system, exposed to typical seismic moment patterns, are insensitive to component strength, the latter can be arbitrarily assigned to them. This enables the astute designer to distribute the required total seismic strength among components so that more economical and practical solutions, satisfying also stipulated displacement limits, are obtained.

- The estimation of displacement capacities of components of a system, such as a coupled wall structure, enables the critical components to be identified. Hence, instead of assuming global ductility factors for structural systems, their displacement and hence ductility capacity should be made dependent on that of the critical component. Such relationships can be established before strengths are assigned to components.

- The approach, illustrated with the aid of an example coupled wall and a frame-wall structure, can be readily incorporated into existing strength-based 
seismic design methods. Its major appeal relates, however, to displacement-based design strategies.

- Coupled wall structures offer distinct advantages such as: (i) very good displacement control, (ii) a strong coupling system allows the use of slender walls without jeopardizing drift limits, (iii) displacement limits during ductile response are not affected by higher mode dynamic effects, (iv) with appropriate detailing of the reinforcement, they can be expected to deliver larger hysteretic damping than any other conventionally constructed reinforced concrete system.

- In the seismic design of ductile structures, bilinear modeling of force-displacement relationships for both components and the system may be considered adequate.

- Moment patterns used for the estimation of deformations of elastic elements are based on typical static lateral force patterns. The fact that force patterns encountered during seismic response may be very different, is not considered to invalidate the approach used for the estimates of displacements in systems dominated by the behaviour or reinforced concrete walls.

- No attempt in this presentation was made to estimate displacement demands. It is the designer's responsibility to establish, with the use of a forcebased or a displacement-based strategy, the level of seismic strength that will ensure that, for a given seismic scenario, the displacement capacity of the system is not likely to be exceeded.

- The approach presented is design rather than analysis oriented. It is based on very simple principles. It is a useful tool in the hands of a designer, which enables, even for mixed structures considered in this study, efficient, practical and simple solutions to be obtained.

\section{ACKNOWLEDGEMENTS}

While carrying out research work at the University of Canterbury relevant to the torsional response of ductile systems, Rolando Castello investigated also momentcurvature relationships which contributed to some of the results presented in Fig. 2. In her research project for the Swiss Federal Institute of Technology in Zürich, carried out at the University of Canterbury, Katrin Beyer inspired the author to rekindle, after some 35 years, his interest in coupled wall structures. A significant part of this presentation was compiled from material prepared by the author for various publications, not readily accessible to design practitioners in New Zealand.

\section{REFERENCES}

1. Priestley, M.J.N. (1995), "Myths and fallacies in earthquake engineering - Conflicts between design and reality", American Concrete Institute, (SP-157)
Recent developments in lateral force transfer in buildings, pp 231-254.

2. Paulay, T. and Priestley, M.J.N. (1992), Seismic Design of Reinforced Concrete and Masonry Buildings, John Wiley and Sons, New York.

3. NZS 3101:1995 Concrete Structures Standard, Part 1 and 2, Standards New Zealand.

4. Priestley, M.J.N., and Kowalsky M.J. (1998), "Aspects of drift and ductility capacity of rectangular structural walls", Bulletin of the New Zealand Society for Earthquake Engineering, Vol. 31, No. 2, pp. 7385 .

5. Priestley, M.J.N. (1998), "Brief comments on elastic flexibility of reinforced concrete frames and significance in seismic design", Bulletin of the New Zealand Society for Earthquake Engineering, Vol. 31, No. 4, pp. 246-259.

6. Paulay, T. (2001), “A Re-definition of the Stiffness of Reinforced Concrete Elements and its Implications in Seismic Design" Structural Engineering International, Vol. 11, No. 1, pp. 36-41.

7. Paulay, T. (2000), "A Simple Displacement Compatibility-based Design Strategy for Reinforced Concrete Buildings" Proceedings $12^{\text {th }}$ World Conference on Earthquake Engineering, Paper No. 0062.

8. Paulay, T. (2001), "Some Design Principles Relevant to Torsional Phenomena in Ductile Buildings", Journal of Earthquake Engineering, Vol. 5, No. 3, pp. $273-30$.

9. Paulay, T. (2001), "The Freedom in Choosing the Seismic Strength of Components", Journal of the Structural Engineering Society New Zealand, Vol. 14, No. 2, pp. 51-56.

10. Paulay, T. (2002), "An Estimation of Displacement Limits for Ductile Systems", Earthquake Engineering and Structural Dynamics, Vol. 31, No. 3, pp. 583599.

11. Paulay, T. (1998), "Torsional Mechanics in Ductile Building Systems", Earthquake Engineering and Structural Dynamics, Vol. 27, pp. 1101-1121.

12. Park, R. and Paulay, T. (1975), "Reinforced Concrete Strucrures", John Wiley and Sons, New York, 769 p.

13. Harries, A.K. (2001), "Ductility and Deformability of Coupling Beams In Reinforced Concrete Coupled 
Walls", Earthquake Spectra, Vol. 17, No. 3, pp. 457 478.

14. Chitty, L. (1947), "On the Cantilever Composed of a Number of Parallel Beams Interconnected by Cross Bars", The London, Edinburgh and Dublin Philosophical Magazine and Journal of Sciences, Vol. 38, pp. 685-699.

15. Coull, A. and Choudhury, J.R. (1964), "Analysis of Coupled Shear Walls", Proceedings ACI Journal, Vol. 64, No. 9, pp. 587-593.

16. Saatcioglu, M., Derecho, A.T., and Corley, W.G. (1987), "Parametric Study of Earthquake-resistant Coupled Walls", ASCE Journal of Structural Division, No. 113, No. 1, pp. 141-157.

17. Paulay, T. (1976), "Ductile Behaviour of Coupled Shear Walls", ASCE Journal of the Structural Division, Vol. 102, ST1, pp. 93-108.

18. Paulay, T. (2001), "Seismic Response of Structural Walls: Recent Developments", Canadian Journal of Civil Engineering, Vol. 28, pp 922-937.

19. Paulay, T. (1972), "Diagonally Reinforced Coupling Beams of Shear Walls", ACI Special Publication, SP42 , Vol. 1, pp. 579-598.

20. Paulay, T. and Sauthakumar, A.R. (1976), "Ductile Behaviour of Coupled Shear Walls", ASCE Journal of the Structural Division, Vol. 102, ST1, pp. 93-108.

21. Santhakumar, A.R. (1974), "Ductility of Coupled Shear Walls", PhD Thesis, University of Canterbury, Christchurch, New Zealand, 412 p.

22. Paulay. T (2002), "A Displacement Focused Seismic Design of Mixed Building Systems", Earthquake Spectra, the Professional Journal of the Earthquake Engineering Research Institute, In press.

23. Rodriguez, M.E., Restrepo, J.I. and Carr, A.J. (2002), "Earthquake-induced Floor Accelerations in Buildings," Earthquake Engineering and Structural Dynamics, Vol. 31, No. 3, pp. 693-718.

24. Priestley, M.J.N. (1998), "Brief comments on elastic flexibility of reinforced concrete frames and significance to seismic design", Bulletin of the New Zealand Society for Earthquake Engineering, Vol. 31, No. 4, pp. 246-259.

25. Priestley, M.J.N., (2000), "Performance based Seismic Design", State of the Art Report, $12^{\text {th }}$ World Conference on Earthquake Engineering, Bulletin of the New Zealand Society for Earthquake Engineering, Vol. 33, No. 3, pp. 325-346.

26. Priestley, M.J.N. and Kowalsky, M.J. (2000), "Direct displacement-based seismic design of concrete buildings", Bulletin of the New Zealand Society for Earthquake Engineering, Vol. 33, No. 4, pp. 421444.

27. Paulay, T. and Binney, J.R. (1974), "Diagonally Reinforced Coupling Beams of Shear Walls", Shear in Reinforced Concrete. ACI Special Publication SP41. Vol. I, pp. 1-15.

28. Aoyama, H. (1987), "Earthquake Resistant Design of Reinforced Concrete Frame Buildings with 'Flexural' Walls", Journal of the Faculty of Engineering, The University of Tokyo (B), Vol. XXXIX, No. 2.

\section{APPENDIX \\ DEFORMATIONS OF COUPLING BEAMS}

As Figure 7 demonstrates, diagonally reinforced coupling beams are intended to transfer internal diagonal forces only. Therefore, the appropriate model, used for estimating their deformations, should be that of a truss, commonly referred to in reinforced concrete structures as "strut and tie" systems. Such a model is shown in Figure A1(a). The prediction of the relative displacements of the boundaries of the beams, shown in Figure 7, may then be based on the approach introduced by Williot and Mohr.

The displacements of distinct points of the beam, such as A, B, C and D in Figure A1(b), need to be related to each other. The elongation and shortening of the diagonals, consistent with assumed axial strains, result in deformations, denoted in Section 5.5 as $\Delta_{T}$ and $\Delta_{C}$, respectively (points $\mathrm{c}^{\prime}$ and $\mathrm{d}^{\prime}$ in Figure $\mathrm{A} 1(\mathrm{~b})$ ). The boundary conditions of the truss model, whereby the vertical boundaries of the beam should remain parallel and the distances $A B$ and $C D$ should not change, need to be satisfied. To this end the tie and the strut must pivot around points $\mathrm{A}$ and $\mathrm{B}$, respectively, resulting in additional displacements $\mathrm{c}^{\prime} \mathrm{c}$ and $\mathrm{d}^{\prime} \mathrm{d}$. The final identical displacements of points $\mathrm{C}$ and $\mathrm{D}$, shown as $\Delta_{\text {toral }}=\mathrm{Cc}$ or $\mathrm{Dd}$ in Figure Al (b), satisfy these boundary criteria. Using the geometric relationships available from Figure A1(b), it may then be shown that the vertical, $\Delta_{v}$, and horizontal, $\Delta_{h}$, displacements of one end of the beam, relative to the other end, are:

$\left.\Delta_{v}=\left(\Delta_{T}+\Delta_{C}\right) / 2 \sin \alpha\right)$

and

$$
\Delta_{h}=\left(\Delta_{T}-\Delta_{\partial}\right) /(2 \cos \alpha)
$$




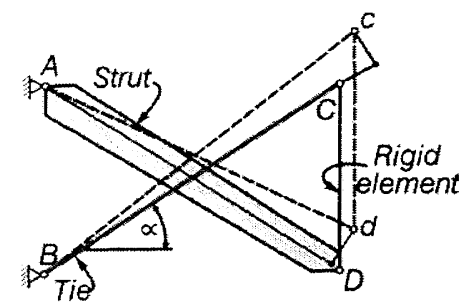

(a) Strut and tie model

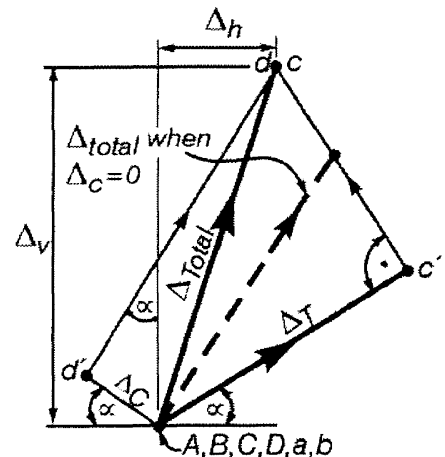

(b) Displacement components
The possible consequences of the horizontal deformation of coupling beams, $\Delta_{h}$, have been briefly reviewed in Section 5.5

To examine the reliability of the above well established theoretical displacement predictions in terms of the nominal yield chord rotation, $\theta_{\text {by }}$, given by Eq. $(15 b)$, the performance of a test beam [27] as recorded 30 years ago, is reproduced in Figure A2. Using the notation defined in Section 5.5, the relevant data are: $s=1016 \mathrm{~mm}, \alpha \approx 28^{\circ}, d_{b}$ $=25.4 \mathrm{~mm}, \epsilon_{\mathrm{y}}=0.00139$. Loads recorded are in terms of the shear force sustained by the beam. From Eq. (14a), $\Delta_{T}=(1016 / 0.88+16 \times 25.4) 0.00139=2.17 \mathrm{~mm}$. Therefore, with the use of Eqs. (15a) and (15b), the estimated nominal yield chord rotation, associated with positive loading of the test beam, is $\theta_{b y}=1.3 \times 2.17 /(2 \times$ $1016 \times 0.469) \approx 0.003 \mathrm{rad}$. Failure of the poorly detailed beam was imminent at the attainment of a displacement ductility of approximately 20 .

Figure A1. Sources of displacements of diagonally reinforced concrete coupling beams

To illustrate the significance of the estimation diagonal compression strains, the total displacement, $\Delta_{\text {total }}$, associated with $\Delta_{C}=0$, is shown by the dashed line in Figure A1(b).

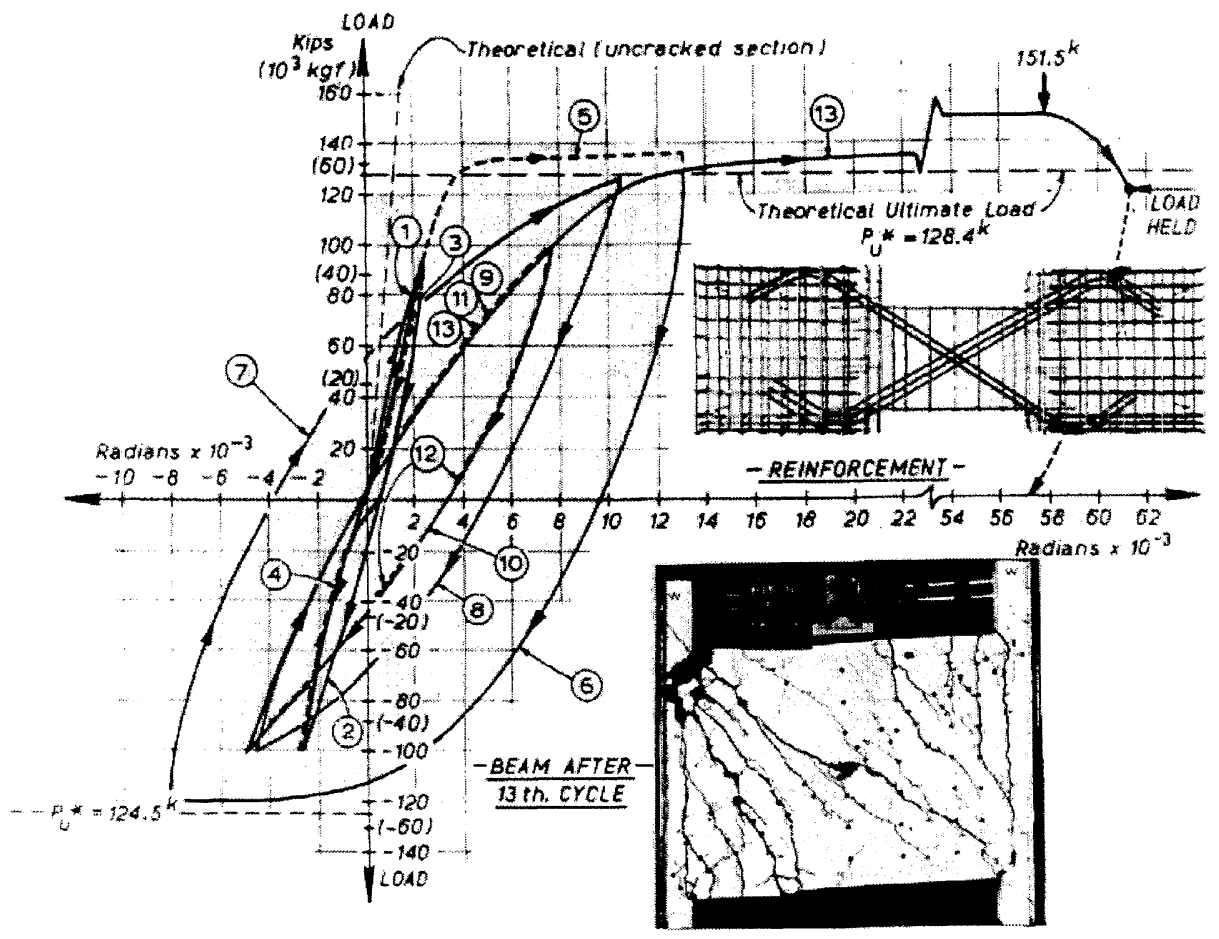

Figure A2. Observed load-rotation relationship for a test beam [27] 